\title{
O professor de ensino médio e a psicologia em seu cotidiano escolar
}

\author{
Professor de ensino médio-psicologia
}

\author{
Rúbia Sousa Almeida \\ Cândida Beatriz Alves \\ Gabriella Nunes Neves \\ Ludmila Pereira Silva \\ Regina Lúcia Sucupira Pedroza
}

\begin{abstract}
Resumo
O contato do professor de Ensino Médio com a Psicologia durante sua formação acadêmica acontece pela Licenciatura e pretende fornecer subsídios para sua prática escolar. Esta pesquisa teve por objetivo analisar a visão desse professor sobre a influência da Psicologia em seu cotidiano, investigando como a preparação oferecida durante a graduação e outras formas de contato com a Psicologia contribuem para o exercício docente. Realizaram-se 30 entrevistas semi-estruturadas com professores do Ensino Médio de escolas particulares e públicas do Distrito Federal. Os dados coletados revelaram que a maioria dos professores esqueceu o que estudou sobre Psicologia. Os entrevistados reconheceram a importância da Psicologia, porém reclamaram da falta de conhecimento para utilizá-la. Os resultados apontam para a pouca eficiência das disciplinas de Psicologia ministradas nas Licenciaturas, que não atingem sua função de intervenção em sala de aula. É urgente uma revisão desse problema, já que essa carência tem sido sentida pelos professores. Palavras-chave: Professor, Ensino Médio, Psicologia
\end{abstract}

\section{The high school educator and the psychology in his everyday school-life}

\begin{abstract}
The contact of high school educators with Psychology during their graduation occurs during the Licensing courses and aims at giving them the basis for school practice. The present research intends to analyze how these teachers view the influence of Psychology in their everyday life, investigating how the current preparation during the period of graduation, as well as other forms of their connection to the science of Psychology contribute for practice. Thirty semi-structured interviews have been recorded with high school teachers from public and private schools of the Federal District. The resulting interviews disclose that most of them forgot what they had learned about Psychology. The interviewed teachers agreed on the importance of Psychology, although they still deplore knowledge gaps on how to make use of it. Results point to low efficiency of Psychology disciplines given in Licensing courses, which do not fulfill its intervention function in classroom properly. Thus, revision on the problem is urgent, since its inadequacy is felt by high school teachers.

Keywords: Teacher, High school, Psychology
\end{abstract}

\section{El profesor de enseñanza secundaria y la psicología en su cotidiano escolar}

\section{Resumen}

El contacto del profesor de Enseñanza Secundaria con la Psicología durante su formación académica se da por la Licenciatura y pretende proporcionar subsidios para su práctica escolar. Esta investigación tuvo como objetivo analizar la visión de ese profesor sobre la influencia de la Psicología en su cotidiano, investigando como la preparación que es ofrecida durante el curso además de otras formas de contacto con la Psicología contribuyen para el ejercicio docente. Se realizaron 30 entrevistas semi-estructuradas con profesores de la Enseñanza Secundaria de escuelas privadas y pública del Distrito Federal. Los datos cosechados mostraron que la mayoría de los profesores se olvidó lo que estudió sobre Psicología. Los entrevistas reconocieron la importancia de la Psicología pero reclamaron de la falta de conocimiento para utilizarla. Los resultados apuntan para un poco eficiencia de las disciplinas de Psicología dadas en la Licenciatura, que no alcanzan su función de intervención en la clase. Es urgente rever ese problema, una vez que las carencias han sido sentidas por los profesores.

Palabras clave: profesor, enseñanza secundaria, psicología, 


\section{Introdução}

O ponto de interseção entre as disciplinas Psicologia e Pedagogia é caracterizado por um histórico de contribuições, desentendimentos e diversidade de idéias. Houve uma época em que muitos teóricos defenderam a supremacia da primeira sobre a segunda, alegando que a análise psicológica seria suficiente para a compreensão dos fenômenos educativos e que a Psicologia da Educação seria, portanto, sua área mais significativa (Coll, Palacios \& Marchesi, 1996). Dessa forma, a posição da Psicologia na sua relação com a Pedagogia aparece, muitas vezes, como uma relação de autoridade, ultrapassando os limites de sua competência (Sass, 2003). Essa hegemonia foi questionada por muitos estudiosos de outras áreas, principalmente da Sociologia, e da própria Psicologia, que defendiam a necessidade de um enfoque multidisciplinar nas questões concernentes à Educação (Merani, 1977; Lima, 1990).

A despeito dessas controvérsias, pode-se dizer que há um consenso de que conhecimentos de Psicologia podem e devem servir de embasamento teórico e/ou instrumento para a prática didática (Fávero, 2005). Lima (1990) reconhece a grande influência da Psicologia sobre a Educação, principalmente por tratar de questões diretamente relacionadas com a aprendizagem e o comportamento humanos. Segundo Piaget (1969/1970), é possível fazer uma analogia da interação entre esses dois campos com a relação entre as ciências médicas e biológicas, em que nenhuma é apenas um ramo da outra, e sim áreas com métodos e problemas específicos. Ele ressalta que uma não deve negligenciar, em prol de seu próprio desenvolvimento, os conhecimentos produzidos pela ciência relacionada. De fato, a Psicologia da Educação é tida como significativa para ambas as disciplinas e consta como conhecimento necessário na formação do professor (Carvalho \& Sadalla, 2002; Larocca, 2002). Essa idéia também é defendida por Wallon (1937), que entende que a relação entre a psicologia e a educação não é a de uma ciência normativa e de uma ciência aplicada.

\section{Psicologia e formação do professor}

A formação dos docentes para atuar na educação básica é regida pela Lei de Diretrizes e Bases da Educação Nacional (LDB), de 1996, que exige curso de nível superior em universidades, institutos superiores de educação e outras instituições congêneres (Nunes, 2002). Como o programa das disciplinas no nível superior é decidido por cada instituição, a lei não faz menção à Psicologia na formação do docente. Nesses cursos, os conteúdos de Psicologia situam-se nos currículos como área pedagógica, visando subsidiar a atuação do professor através do conhecimento dos processos de desenvolvimento e aprendizagem. Geralmente, são ministrados na disciplina Psicologia Educacional, que se destaca pela presença marcante nos currículos das Licenciaturas. Apesar de não ser a única a tratar do tema, é considerada de referência nos cursos superiores (Silva, 2003).

Os conteúdos específicos transmitidos ao educador em formação também foram alvo de discussões e modificações ao longo da história da disciplina Psicologia da Educação. Inicialmente, a ênfase era dirigida às fases de desenvolvimento e processos de aprendizagem do aluno. Era-se esperado, então, que o professor, de posse desse embasamento teórico, atuasse de acordo com as potencialidades e limitações do discente (Foulin \& Mouchon, 1999; Bacchiega, Pina, Sadalla \& Wisnivesky, 2002). Segundo Coll (1999), é possível observar um deslocamento dessa ênfase para o interesse nas questões relacionadas à instrução e à formação de professores. Em outras palavras, esse movimento se dá a partir do educando para o educador e envolve, conseqüentemente, uma reformulação do campo. Atualmente, a formação ideal do professor pressupõe também a estruturação de uma rede de posturas, conhecimentos, atitudes e crenças acerca do seu próprio trabalho e de sua interação com o aluno (Nóvoa, 1992).

Pedroza (2003), ao estudar a formação de professores segundo uma ótica materialista-dialética, defende a importância da Psicologia na formação da pessoa do professor, no desenvolvimento de sua personalidade em prol da construção de um educador prático-reflexivo. Esse professor é aquele que transforma o exercício pedagógico em um constante pensar e repensar de sua atuação, articulando, de forma 
dialética, a pesquisa e a prática. Guerra (2000) é outra autora que enfatiza a necessidade de uma formação não apenas profissional, mas também pessoal de educadores mais autônomos e conscientes, ressaltando ainda que o ensino de Psicologia nos cursos de Licenciatura pode favorecer esse processo.

Apesar do crescente reconhecimento, no meio científico, da indissociabilidade do desenvolvimento profissional e pessoal do professor, Nóvoa (1992) afirma que a necessidade de se estimular a postura crítico-reflexiva e o pensamento autônomo do educador tem sido ignorada. De fato, não é difícil perceber que o ensino de Psicologia nos cursos de formação docente continua restrito à transmissão de conteúdos referentes aos processos de desenvolvimento e aprendizagem do aluno (Guerra, 2000). Silva (2003) afirma que essa forma de transmissão perpetua uma concepção dicotomizante do processo de ensino-aprendizagem, levando o educador a "perceber o processo de aprender do aluno como algo individual, sem relação, portanto, com o seu trabalho, o ensinar" (p. 30). Esse sub-aproveitamento de conhecimentos psicológicos na formação do educador pode ser entendido face à crença difundida de que a Psicologia serviria apenas de base teórica para a prática pedagógica (Pedroza, 2003). Isso se evidencia no fato das disciplinas com conteúdo de Psicologia serem vistas no início dos cursos de Licenciatura, quando o estudante ainda está distante da realidade escolar que irá vivenciar (Larocca, 1996).

Vários estudos realizados com licenciandos (Branco, 1988; Fini, 1987; Larocca, 1996; Putini, 1988; Kullok, 2000) sinalizam que as principais críticas à disciplina Psicologia da Educação se referem à: descontextualização da realidade, desarticulação entre teoria e prática, insuficiência da carga horária e ausência de vinculação entre o conteúdo psicológico e a área específica do curso do futuro professor. Tudo isso culmina em um sentimento de frustração ao final da disciplina (Fini, 1987). No entanto, apesar das críticas, pesquisas mostram que os conhecimentos de Psicologia são considerados indispensáveis ao processo educativo pelos próprios estudantes licenciandos (Larocca, 1996; Guerra, 2000) e por professores já atuantes (Rodrigues \& Esteves, 1993).
Pode-se inserir nesta discussão o papel do psicólogo escolar enquanto facilitador da interação alunoprofessor. Segundo Patto (1987), a psicologia escolar esteve historicamente associada à mensuração de habilidades e à classificação das crianças quanto à sua capacidade de aprender e de progredir nos estudos. Em um segundo momento, que se estende até o presente, os psicólogos na escola assumem a orientação clínica, ocupando-se de diagnosticar e tratar distúrbios em alunos. Essa forma de atuação, no entanto, cria uma dicotomia artificial entre o processo de aprendizagem e as relações sociais existentes na escola (Souza, 1997). A necessidade desse profissional dá-se justamente no sentido de criar espaços para diálogo e reflexão entre todos os atores envolvidos no processo educacional, entre eles o professor. Dessa forma, o psicólogo estaria envolvido no desenvolvimento profissional e pessoal do docente, contribuindo para uma postura crítico-reflexiva desse último com relação ao seu próprio trabalho (Pedroza, 2003).

Portanto, a reflexão sobre a importância do psicólogo escolar para o presente trabalho se dá enquanto possibilidade de uma atuação na formação continuada do professor, tanto no que diz respeito à prática em sala de aula como nas questões específicas da adolescência.

Partindo da constatação de Almeida (2000) da escassez de material de pesquisa acerca da relação do professor de Ensino Médio com a Psicologia, a presente pesquisa objetivou: analisar a visão do referido docente sobre a influência dessa ciência em seu cotidiano escolar, investigar de que maneira os conhecimentos de Psicologia adquiridos na licenciatura contribuem na vivência profissional e pessoal do professor, questionar e refletir o ensino de Psicologia nas Licenciaturas. Por fim, constituiu-se ainda um interresse de análise a visão do professor de Ensino Médio acerca da interação com um eventual psicólogo escolar.

\section{Método}

\section{Participantes}

Foram entrevistados 30 professores atuantes no Ensino Médio do Distrito Federal, sendo metade per- 
tencente a instituições particulares e a outra, a públicas. Do total da amostra, 13 eram do sexo feminino e 17 do masculino. 21 lecionavam disciplinas na área de humanas e nove na área de exatas, cobrindo, praticamente, todas as matérias do Ensino Médio.

As instituições selecionadas foram quatro particulares e três públicas, sendo todas localizadas no Plano Piloto, considerado centro habitacional pertencente a um nível sócio-econômico de renda elevada.

Dos entrevistados, 24 eram licenciados, dois com a Licenciatura em andamento e quatro não licenciados. Serão consideradas as entrevistas destes últimos tendo em vista o objetivo de verificar a importância da Psicologia na formação, e de que modo a falta dela poderia ter interferido na prática desses docentes.

Os participantes também foram classificados quanto ao tempo de profissão, sendo divididos em três grupos: o primeiro, de I a 10 anos, com nove participantes; o segundo, de II a 20 anos, com 12 profissionais; e o terceiro, de mais de $2 \mathrm{I}$ anos de profissão, com nove sujeitos.

\section{Instrumento}

Foi utilizada uma entrevista semi-estruturada, cujo roteiro baseava-se em três partes. Na primeira, coletaram-se dados acerca da formação do professor, tais como tempo na profissão, tempo na escola atual e o tipo de formação; a segunda baseou-se em duas perguntas: a importância atribuída pelo professor à Psicologia e seus aspectos com os quais teve contato durante sua formação acadêmica; já a terceira parte foi composta por perguntas sobre a Psicologia no cotidiano escolar do docente: a existência ou não de um psicólogo escolar, sua interação com esse profissional, sua relação com o aluno e com a Psicologia e as atitudes do educador em sala de aula. Além disso, durante as entrevistas, foram feitas outras perguntas de acordo com temas surgidos nas respostas dos professores.

\section{Procedimento}

Das 30 entrevistas, 27 foram gravadas em áudio e transcritas. As restantes foram apenas registradas por escrito no ato da entrevista devido a recusa de um professor, e a falhas no gravador.
A partir das transcrições das entrevistas, foi feito um levantamento da idéia principal de cada resposta dada, com o objetivo de posteriormente categorizar e fazer uma análise qualitativa dos dados. Utilizou-se - método de análise de conteúdo (Bardin, 1977; Giglioni \& Matalon, 1978) segundo o qual as falas dos professores são agregadas nas unidades de significação mais características de cada resposta constante nas entrevistas.

\section{Resultados e Discussão}

Os resultados apresentados a seguir estão dispostos em tópicos fundamentados nas respostas dadas pelos professores nas entrevistas, de modo que cada um agrupa um tema bem delineado.

\section{Importância da psicologia}

A Psicologia durante a formação acadêmica foi investigada por meio de questões relativas ao conteúdo programático e de que maneira isso contribuiu no desenvolvimento profissional de cada um dos entrevistados. A maioria dos educadores que tiveram algum tipo de contato com conhecimentos de Psicologia durante sua formação criticou o conteúdo e a forma como foi ministrado. As principais reclamações foram referentes à insuficiência do programa, à sua superficialidade e à dicotomia teoria e prática. "[...] então você não aprende o beabá, você escuta alguém falando do $x$ y $z$ ! E com isso você acaba tendo uma vaga idéia mas não é algo que você consegue absorver e transformar em prática pedagógica. Eu pelo menos não consegui." Esses dados estão de acordo com aqueles encontrados por Fini (1987), Branco (1998), Putini (1988), Larocca (1996), no que diz respeito às principais críticas aos conteúdos de Psicologia vistos durante a formação dos docentes. Apesar disso, não foram encontradas menções à descontextualização da realidade e à ausência de vinculação entre o conteúdo de Psicologia e a área específica do futuro professor. Acredita-se, no entanto, que esses fatores estão presentes de modo implícito no descontentamento generalizado que os entrevistados demonstraram frente ao tema. 
De maneira geral, os professores revelaram-se decepcionados com os conteúdos de Psicologia vistos na Licenciatura e principalmente à forma como foram ministrados. "Olha, esse contato não serviu pra nada, talvez tenha até atrapalhado. Agora, talvez se eu tivesse tido uma aula de psicologia adequada ...", "Não aprendi nada na Licenciatura que me ajudasse dentro da sala de aula", "Se as pessoas soubessem passar pra gente, seria muito bom". Pode-se verificar pelos discursos acima que a Psicologia na Licenciatura ainda é incipiente. É notável que os entrevistados percebem a importância e sentem a necessidade de adquirir subsídios de Psicologia para sua prática, consonante com o encontrado por Rodrigues e Esteves (1993), Larocca (1996) e Guerra (2000). Entretanto, a maneira como o tema vem sendo tratado não tem atendido essa carência. Em outras palavras, encontra-se um sentimento de frustraçãom conforme relata Fini (1987).

Outra reclamação dos professores, também descrita por Silva (2003), diz respeito à ênfase dada aos aspectos voltados à infância, o que os leva a caracterizar a Psicologia na Licenciatura como pouco relevante para a faixa etária dos alunos de Ensino Médio. Muitos manisfestam a opinião de que os conteúdos de Psicologia deveriam abranger mais temas relacionados ao adolescente e às transformações pelas quais eles passam. "Nunca se pensa em Psicologia do adolescente, do adulto, nunca se pensa nisso. [...] Fala do desenvolvimento da criança, da língua, da alfabetização, mas não fala do desenvolvimento do adolescente".

É possível dividir os entrevistados entre aqueles que não se lembravam de nada do que haviam visto sobre Psicologia durante a graduação, aqueles que se recordavam de alguns pontos, porém não o relacionavam à sua prática escolar e, por fim, aqueles que, lembrandose $d$ emuito do que fora aprendido, eram capazes de vincular esses conhecimentos ao processo educacional. No entanto, as críticas destacadas neste tópico permearam com seu curso de Licenciatura.

Com relação aos professores que disseram se lembrar de conteúdos de Psicologia vistos durante a formação, cinco deles alegaram que não seriam hoje os mesmos profissionais caso não tivessem tido esse contato. Para eles, essas contribuições se deram prin- cipalmente no sentido de saber o que esperar do estudante e compreender as especificidades da fase de desenvolvimento pela qual ele está passando, como pode ser observado na seguinte fala: "A questão do entendimento do indivíduo, da socialização, a questão do fato social, quem é o indivíduo, qual sociedade que ele tá inserido, o tipo de comportamento que se espera dele". Ou ainda: "O importante é que eu posso entender o aluno, pra que eu possa saber o que cobrar, onde cobrar e saber qual resposta que eu vou esperar dele". De modo geral, esses professores afirmaram que a Psicologia ajudou-os a formular um modo de trabaIhar com o alunado, dando-lhes embasamento teórico. "Acredito sim que, tendo essa informação dentro da psicologia, a gente tem mais facilidade em sala de aula". É importante destacar que todos os professores aqui referidos relataram possuir um conhecimento de Psicologia que foi adquirido de outra forma além das disciplinas da Licenciatura, seja no magistério, em leituras, em cursos extras ou em uma graduação incompleta na área. Este fato corrobora a necessidade de se pensar a formação do rpofessor além do conteúdo acadêmico e salienta a importãncia do desenvolvimento pessoal do docente (Nóvoa, 1992; Pedroza, 2003).

Outra questão abordada durante a entrevista e que diz respeito à formação do educador pretendeu investigar a concepção dos docentes acerca do que é necessário para ser um bom professor. $O$ ponto mais mencionado - tanto por licenciados quanto por nãolicenciados - foi a formação acadêmica, que esteve, porém, fortemente associada com a menção à experiência e à prática em sala de aula. "Qualquer um pode se tornar um bom professor [...], depende da preparação, da dedicação do professor. $O$ básico é ter uma boa formação".

Observa-se que os entrevistados percebem a formação acadêmcia como um recurso desejável - ou ainda um insumo necessário - à construção de um profissional de qualidade e valorizado como tal. No entanto, a experiência em sala de aula é muitas vezes destacada como o único fator indispensável para o desenvolvimento de um bom educador. A necessidade percebida aqui de um vínculo estreito entre formação de experiência pedagógica - ou pode-se dizer, 
entre teoria e prática - revela mais uma vez a importância de que esses dois aspectos da profissão estejam intimamente articulados.

Um número menor de professores atribuiu a construção de um bom professor a um dom ou vocação, sem os quais mesmo a melhor formação seria inútil. "[...] por melhor formação que você tenha, não se garante que vai ser um bom professor [...] então, sorte não é, boa formação acadêmica também não. Ajuda muito, mas quando você já tem a vocação para aquilo" "Ser professor hoje é um dom [...]Tem que ter carisma, tem que ter didática, tem que ser um bom profissional, tem que ter dom pra dar aula". É possível inferir nessa última fala que o carisma, a didática, o profissionalismo e a habilidade para dar aula são colocados sob o signo de dom. Tal visão determinista engessa o desenvolvimento do educador em uma simples avaliação daqueles que possuem ou não o talento natural para a profissão, funcionando, ao mesmo tempo, como uma acomodação e justificativa para maus desempenhos. Percebe-se aqui, mais uma vez, a função essencial da Licenciatura no que diz respeito a desmistificar essa postura fatalista, dando subsídios ao desenvolvimento do bom professor (Larocca, 2002).

Quando perguntado aos docentes se era buscado algum conhecimento adicional de Psicologia, foram mencionados livros, congressos, seminários e terapia. Chama a atenção que 12 entrevistados não buscam nenhum conhecimento adicional e, a partir desse dado, essa questão pode ser somada à pouca importância atribuída à Psicologia enquanto propulsora de contribuição tanto para prática quanto para a formação continuada. Além disso, percebe-se a pouca importância dada à pesquisa por muitos professores, aspecto mencionado por Oliveira e Azzi (2002) como essencial para uma postura reflexiva diante da atuação profissional.

\section{Importância da psicologia}

Percebe-se na fala dos professores uma acentuada associação entre a Psicologia e a figura do aluno, expressada através do recorrente relato acerca da compreensão e forma de lidar com o discente. "O importante é porque eu posso entender melhor o aluno [...] Pra isso é importante entender a fase que ele está, as dificuldades que está passando". O enfoque dado aos alunos é ressaltado também na preocupação com as diferenças individuais entre esses. "Uma discussão que eu acho fundamental que a Psicologia traz à tona é a discussão da alteridade, porque você está lidando também com a questão da diferença em sala de aula". Além disso, é possível notar uma forte associação entre a Psicologia e a forma de motivar o estudante, além da compreensão das mudanças características do seu desenvolvimento. "Se eu estou me propondo a ensinar alguém, o mínimo que se espera é que eu saiba como é que esse alguém aprende".

De modo geral, as opiniões dos professores destacaram que a Psicologia poderia auxiliar a trabalhar a auto-estima dos alunos, sua criatividade, processos de aprendizagem e problemas familiares. Respostas desse tipo apontam para a posição, tanto dos licenciados quanto dos não-licenciados, de que a dinâmica escolar e os problemas educacionais concentram-se especialmente no aluno e sua postura frente ao contexto pedagógico. " $\mathrm{O}$ verdadeiro protagonista da educação é o aluno, se ele não se abrir para o aprendizado, em vão trabalharão psicólogos, professores. É uma coisa que vem mesmo de dentro". Esse achado corrobora a afirmação de Guerra (2000) de que o conteúdo de Psicologia ministrado nos cursos de formação docente se limita a questões que enfocam o aluno. Apesar de marcante na literatura científica da área a necessidade da atenção voltar-se também para o professor (Nóvoa, 1992; Pedroza, 2003), esta ainda não é a realidade educacional.

Poucas foram as colocações que mencionavam a Psicologia como recurso para melhorar a atuação do professor. No entanto, quando presentes, foram muito enfatizadas e levantadas repetidas vezes ao longo de toda a entrevista. Isso sugere que, uma vez percebida essa contribuição, ela reflete a necessidade sentida pelo educador de auxílio no processo de autoconhecimento e na construção de uma postura confiante para a sala de aula. Cabe a observação de que mais da metade dos não-licenciados expuseram essa possibilidade de contribuição, enquanto apenas uma minoria de licenciados o fez. Essa constatação dá margem para se pensar a Licenciatura como insuficiente para dar conta da ampla gama de conhecimen- 
tos de Psicologia pensados para o desenvolvimento, não só profissional do educador, mas também - e principalmente - pessoal do indivíduo por trás dessa figura (Guerra, 2000; Nóvoa, 1992; Pedroza, 2003).

Paralelo a esse dado, outro resultado interessante diz respeito às várias associações feitas pelos próprios entrevistados entre a sua profissão e a de um psicólogo. Essas colocações se encontram no discurso por vezes de maneira explícita como: "acho até que o meu trabalho aqui é um trabalho de psicólogo" ou "sou psicólogo mais na prática mesmo, porque na teoria não"; ou de modo tácito como: "Eu respeito muito o lado das pessoas e procuro muito ajudar [...], então eu sou assim, essa é a minha psicologia que está no ar aí". Observa-se com esses relatos que a visão que o professor tem do profissional psicólogo muitas vezes baseia-se em estereótipos do senso-comum, como sendo aquele que apenas escuta, conversa e dá conselhos bem intencionados. Mais uma vez, nos deparamos com um ponto crucial de questionamento à maneira como a Psicologia vem sendo ministrada nos cursos de Licenciatura. Esse questionamento se refere principalmente ao insucesso em transmitir para os futuros professores o intercâmbio rico e necessário que deve existir entre as ciências Psicologia e Pedagogia (Wallon, 1937; Piaget, 1969/1970).

Houve também um número reduzido (dois licenciados e um não-licenciado) que não atribuiu nenhuma importância à Psicologia para sua prática pedagógica: "eu não creio muito em Psicologia, não. Sério, eu acho que essa questão de ficar trabalhando com conversinhas não dá [...] na minha opinião, é muito superficial". Aqui é possível notar, mais uma vez, o desconhecimento do campo teórico e de atuação da Psicologia, e de como essa ciência poderia contribuir para a formação do educador.

\section{A atuação do psicólogo escolar}

As perguntas referentes à atuação do psicólogo escolar permitem dividir os entrevistados em dois grupos: aqueles que dispõem desse profissional na escola em que trabalham e aqueles que não dispõem. O primeiro grupo, composto por 18 professores de escolas públicas e particulares, atribuiu o trabalho do psicólogo principalmente à intervenção junto ao alu- no com problemas, seja de aprendizagem ou de comportamento. Dessa forma, o papel desse profissional nas escolas estaria relacionado com orientação, conversa e ajuda na resolução de problemas de origem familiar, afetiva ou escolar. Esse achado pode ser vinculado à concepção mencionada no primeiro tópico de que a Psicologia teria como contribuição apenas os conhecimentos referentes ao discente. Além disso, os dados aqui descritos estão de acordo com a afirmação de Patto (1987) de que, atualmente, a Psicologia na escola ainda é tida como um recurso clínico para tratar problemas estudantis. "É... o psicólogo aqui atende os alunos que têm mais problemas, eles vão pra sala dele, usando o método dele e tal. $E$ às vezes funciona".

Os demais professores, ainda do primeiro grupo, se referiram ao trabalho do psicólogo escolar como o de facilitador da interação professor-aluno. No entanto, persiste o foco no discente aparentemente em situação de desajuste, sendo a atuação do psicólogo aqui a de trazer ao professor informações concernentes à vida escolar e extra-escolar do referido estudante. Esses dados podem a princípio parecer distintos dos anteriores, porém uma análise mais aprofundada da fala dos docentes sugere que ambos tratam de uma mesma questão: a adequação do aluno no contexto de sala de aula. "[o trabalho da psicóloga escolar] vem se somar com ao meu trabalho. Muitas vezes, inclusive, explicando, esclarecendo para mim determinadas atitudes, determinados comportamentos que o aluno pode apresentar".

Não houve respostas que mencionassem o trabaIho do psicólogo escolar junto à figura do professor. Em outras palavras, nenhum dos entrevistados vislumbrou a maneira como os dois profissionais poderiam interagir a fim de promover uma melhoria do trabalho docente. É interessante ressaltar que, mesmo aqueles que enfatizaram a contribuição da Psicologia como recurso para otimizar a atuação do educador, não colocaram a figura do psicólogo escolar como possibilitador dessa melhoria.

Ao segundo grupo, composto pelos professores que não dispunham de um psicólogo escolar na instituição em que trabalham, as perguntas foram adaptadas no sentido de investigar como deveria ser a atuação 
desse profissional. Pôde-se observar que não houve muita divergência entre os grupos. Essa semelhança pode ser relacionada ao fato de grande parte desses professores atribuírem ao orientador educacional o papel de psicólogo escolar. "Já tivemos uma psicóloga. Hoje nós temos orientador educacional que faz o papel do psicólogo. Ele não é psicólogo, não é formado em Psicologia, mas orienta". Desse modo, infere-se que, para esses professores, não há distinção funcional entres esses dois profissionais. Além disso, percebese que o professor, estando em contato com o psicólogo escolar ou orientador educacional, continua sem auxílio para refletir a sua prática pedagógica.

Análogo ao primeiro grupo, no segundo não houve também respostas explícitas que destacassem o trabaIho do psicólogo escolar junto ao educador. Porém, uma colocação interessante pode ser observada na seguinte fala: "[...] o papel do psicólogo escolar na minha opinião não é muito bom, porque escola não é lugar de terapia. Ele deveria ajudar a pensar a questão do ensino. Poderia contribuir com a questão do comportamento propondo projetos adequados àquela comunidade". Pode-se perceber aqui que esse professor compartilha da opinião que atribui ao psicólogo escolar o papel de um clínico - alguém que lida com problemas e dificuldades - no contexto educacional. Ao mesmo tempo, porém, critica essa condição, sugerindo um trabalho que vincule o processo de transmissão de conhecimento à realidade social daquele contexto, o que envolve, necessariamente, a figura do professor. Isso mostra, associada a uma crítica, também uma carência de suporte ao próprio educador.

Apenas dois entrevistados não conseguiram vislumbrar nenhuma contribuição de um psicólogo na instituição educacional.

\section{Considerações Finais}

É esperado de um professor que este saiba articular aquilo que aprendeu na graduação com a realidade com a qual se depara em seu cotidiano escolar, bem como apresentar uma postura confiante e crítica diante de sua experiência pedagógica. No entanto, vemos claramente com essa pesquisa que esse é um ideal ainda longe de ser alcançado. $O$ discurso dos professores entrevistados apresenta-se repleto de inseguranças, estigmas, conservadorismos e carências, mas o ponto mais marcante é, sem dúvida, seu tom solitário, afastado. Os docentes mostram-se entregues a seus próprios esforços, o que não deve ser confundido com uma pretensa autonomia e liberdade, mas sim com um abandono, que transparece, em nível macroscópico, o próprio abandono a que é relegada a formação dos professores brasileiros.

Mais especificamente, os resultados obtidos no presente estudo são contundentes ao escancarar o limbo em que se encontra a formação dos professores de Ensino Médio. Submetidos a uma formação alienada e alienante, esses professores não têm outra opção senão se voltar para conhecimentos do senso comum ou para uma simples transposição do que aprendem sobre a infância para a adolescência. Dessa forma, sua atuação em sala de aula é calcada sobre um terreno incerto, dúbio e estereotipado, o que acaba levando os educadores a acreditar que é necessário mesmo um dom - ou seria melhor dizer sorte? - para acertar na postura que apresenta meIhores resultados. A única lembrança que parece lhes restar dos anos de graduação é que a responsabilidade do sucesso ou malogro de uma boa educação recai sobre o aluno, ou pelo menos que é nele que está a chave para um ensino de qualidade.

Ao ressaltar-se aqui a necessidade da atenção voltar-se também para o professor, não estamos pretendendo que o aluno seja esquecido, pelo contrário. Acredita-se que o processo educacional é uma interação, uma relação dialética, já que o professor necessita do aluno para se constituir enquanto tal, bem como o aluno não pode ser concebido na ausência de um docente. Por esse motivo, ambos devem ser sempre entendidos em sua condição relacional. É justamente aqui que recai a nossa crítica sobre o ensino de Psicologia nas Licenciaturas: o modo dicotomizante como ele tem sido estruturado parece subjugar o professor à figura do aluno, deixando o docente sem amparo para a formação de sua pessoa. Nesse ponto, parece-nos crucial a importância que a Psicologia tem enquanto criadora de um espaço de reflexão para o futuro professor, além de um instrumento para a 
compreensão desse caráter relacional que estamos pontuando aqui.

Além dessa contribuição da Psicologia proposta para as Licenciaturas, sugere-se que investigações e intervenções acerca da representação feita do papel do psicólogo escolar pelo professor sejam feitas, a fim de que esse profissional tenha seu trabalho reconhecido e aplicado adequadamente nas instituições escolares. $O$ mesmo atuará como um possibilitador da articulação entre escola, alunos, família e comunidade em geral, que contribua para uma relação educacional mais construtiva. Propõe-se, então, que o papel do psicólogo escolar seja repensado enquanto o de um profissional atuante na formação continuada do professor.

Uma das questões mais importantes reveladas na presente pesquisa, a nosso ver, é a carência sentida pelos professores de Ensino Médio de uma contribuição efetiva da Psicologia, seja enquanto instrumento para o desenvolvimento da personalidade do docente, ou como um auxílio para a compreensão do que ocorre em sala de aula. Se associar essa falta anunciada pelos educadores ao seu desejo da constante articulação entre teoria e prática, chegamos à conclusão de que a Psicologia deve sim atuar como algo mais que um mero pano de fundo teórico. É urgente que as disciplinas responsáveis por abordar conteúdos de Psicologia nas Licenciaturas sejam realocadas em períodos concomitantes com os estágios do futuro professor, de modo que elas caminhem juntas com suas experiências profissionais. No entanto, esse remanejamento não é o suficiente. Além disso, deve haver uma reformulação nessas matérias no sentido de adequá-las às demandas da realidade social e política que o docente irá enfrentar, bem como de estimular o estudante a confrontar o que está aprendendo com as vicissitudes de sua futura prática profissional.

\section{Referências}

Almeida, P. C. A. (2000). Discutindo a relação professor-licenciado e aluno-adolescente à luz da formação em psicologia. Em R.G. Azzi, S. H. S. S. Batista \& A. M. F. A. Sadalla (Orgs.), Formação de professores - Discutindo o ensino de Psicologia (pp. 97-I 18). Campinas: Alínea.
Bacchiega, F., Pina, T. A., Sadalla, A. M. F. A., \& Wisnivesky, M. (2002). Psicologia, licenciatura e saberes docentes: identidade, trajetória e contribuições. Em R. G. Azzi \& A. M. F. A. Sadalla (Orgs.), Psicologia e formação docente: desafios e conversas (pp. 47-92). São Paulo: Casa do Psicólogo.

Bardin, L. (1977). L'analyse de contenu. Paris: PUF.

Branco, L. M. C. (1988). Psicologia para quê? - a psicologia ensinada e a psicologia praticada - subsídio para a compreensão do papel do professor. Tese de Doutorado, Universidade de São Paulo, São Paulo.

Carvalho, L. C., \& Sadalla, A. M. F. A. (2002). Psicologia e formação docente no espaço cotidiano do educador: relato de uma experiência. Em R. G. Azzi \& A. M. F. A. Sadalla (Orgs.), Psicologia e formação docente: desafios e conversas (pp. 293322). São Paulo: Casa do Psicólogo.

Cole, M., \& Cole, S. R. (2004). O desenvolvimento da criança e do adolescente (M. F. Lopes, Trad.). Porto Alegre: Artmed. (Trabalho original publicado em 200I).

Coll, C. (1999). Psicologia da Educação. Porto Alegre: Artmed.

Coll, C., Palacios, J., \& Marchesi, A. (Orgs.). (1996). Desenvolvimento psicológico e educação - Psicologia da Educação. (Vol. 2). Porto Alegre: Artmed.

Costa, A. C. G. (200I). O professor como educador: um resgate urgente e necessário. Salvador: Fundação Luís Eduardo Magalhães.

Fávero, M. H. (2005). Psicologia e conhecimento: Subsídios da psicologia do desenvolvimento para a análise de ensinar e aprender. Brasília: Editora Universidade de Brasília.

Fini, L. D. T. (1987). A situcionalidade da Psicologia Educacional - adolescência nos cursos de licenciatura da UNICAMP. Tese de Doutorado, Pontifícia Universidade Católica de São Paulo, São Paulo.

Foulin, J-N., \& Mouchon, S. (1999). Psychologie de L'éducation. Paris: Éditions Nathan.

Giglioni, R. \& Matalon, B. (1978). Les enquêtes sociologiques: théories et pratiques. Paris: Armand Colin.

Guerra, C. T. (2000). Conhecimento psicológico e formação de professores. Em R.G. Azzi, S. H. S. S. Batista \& A. M. F. A. Sadalla. Formação de professores - Discutindo o ensino de Psicologia (pp. 69-96). Campinas: Alínea.

Kullok, M. G. B. (2000). Formação de professores para o próximo milênio: novo locus? São Paulo: Annablume. 
Larocca, P. (1996). Conhecimento psicológico e séries iniciais: diretrizes para formação de professores. Dissertação de Mestrado, Universidade Estadual de Campinas, Campinas.

Larocca, P. (2002). Problematizado os contínuos desafios da psicologia na formação docente. Em R. G. Azzi \& A. M. F. A. Sadalla (Orgs.), Psicologia e formação docente: desafios e conversas (pp. 3 I-46). São Paulo: Casa do Psicólogo.

Libâneo, J. C. (1998). Adeus professor, adeus professora? Novas exigências educacionais e profissão docente. São Paulo: Cortez.

Lima, E. C. A. S. (1990). O conhecimento psicológico e suas relações com a educação. Em Aberto, ano 9, 48, 3-24.

Merani, A. L. (1977). Psicologia e Pedagogia (As idéias pedagógicas de Henri Wallon). Lisboa: Editorial Notícias.

Nóvoa, A. (Org.). (1992). Os professores e sua formação. Lisboa: Publicações Dom Quixote.

Nunes, C. (2002). Diretrizes Curriculares Nacionais: Ensino Normal - Formação de professores. Rio de Janeiro: DP\&A.

Patto, M. H. S. (1987). Psicologia e ideologia: uma introdução crítica à psicologia escolar. São Paulo: T.A.Queiroz Ltda.

Pedroza, R. L. S. (2003). A Psicologia na formação do professor: uma pesquisa sobre o desenvolvimento pessoal de professores do Ensino Fundamental. Tese de Doutorado, Universidade de Brasília, Brasília.

Perrenoud, P. (2002). A prática reflexiva no ofício de professor: Profissionalização e razão pedagógica. (C. Schilling, Trad.) São Paulo: Artes Médicas. (Trabalho original publicado em 200I).
Piaget, J. (1970). Psicologia e Pedagogia. (D. A. Lindoso, Trad.) Rio de Janeiro: Editora Forense Universitária. (Trabalho original publicado em 1969).

Putini, E. F. (1988). O ensino de Psicologia aplicada a educação no curso de habilitação magistério. Dissertação de Mestrado, Pontifícia Universidade Católica de São Paulo, São Paulo.

Rodrigues, A., \& Esteves, M. (1993). A análise de necessidades na formação de professores. Lisboa: Porto Editora.

Sass, O. (2000). Educação e Psicologia social: uma perspectiva crítica. São Paulo em Perspectiva, 14, 57-64.

Sass, O. (2003). Problemas da educação: o caso da psicopedagogia. Educação \& Sociedade, 24, | 363- 1373.

Silva, A. A. (2003). Contribuições da disciplina Psicologia da Educação segundo professores do Ensino Médio. Dissertação de Mestrado, Universidade de Brasília, Brasília.

Souza, M. P. R. S. (1997). As contribuições dos estudos etnográficos na compreensão do fracasso escolar no Brasil. Em A. M. Machado \& M. P. R. S. Souza. (Orgs.), Psicologia escolar: em busca de novos rumos (pp. 139-156). São Paulo: Casa do Psicólogo.

Wallon, H. (1937). Psychologie et éducation de I'enfance. Enfance, 3(4). 195-202.

Recebido em: I4/06/2006

Revisado em: 12/03/2007

Aprovado em: 19/04/2007

Sobre as autoras:

Rúbia Sousa Almeida (rubia.almeida@gmail.com) é graduanda em Psicologia pela Universidade de Brasília.

Cândida Beatriz Alves (candida.alves@gmail.com) é graduanda em Psicologia pela Universidade de Brasília.

Gabriella Nunes Neves (gabriellanunes@hotmail.com) é graduanda em Psicologia pela Universidade de Brasília.

Ludmila Pereira Silva (lud_mila87@yahoo.com.br) é graduanda em Psicologia pela Universidade de Brasília.

Regina Lúcia Sucupira Pedroza (rpedroza@unb.br) é professora doutora do Instituto de Psicologia da Universidade de Brasília.

Endereço para correspondência:

Regina L. S. Pedroza

Colina Bloco H apt 302

70910-900 - Brasília-DF 